\title{
VALIDEZ FORMAL Y VALIDEZ SUSTANTIVA: EL ENCAJE DE LA COMPETENCIA MATERIAL
}

\author{
Ángeles Ródenas Calatayud \\ Universidad de Alicante
}

RESUMEN. En este trabajo se analizan tres nociones que son usualmente utilizadas por los juristas cuando se ocupan del problema de la validez de las normas jurídicas. Se trata de las nociones de validez formal, de validez material o sustantiva y de competencia material. Tomando como punto de partida los términos en los que los juristas trazan habitualmente la distinción entre validez formal y validez material, en el trabajo se aborda el problema del encaje de competencia material, así como las similitudes y diferencias entre los juicios de validez material y los de competencia material.

Palabras clave: validez jurídica, validez formal, validez material, validez sustantiva, competencia material.

ABSTRACT. In this paper the author analyzes three notions that are usually used by lawyers when dealing with the problem of the validity of legal norms. These are the notions of formal validity, substantive or material validity and material competence. Taking as starting point the way in which lawyers usually draw the distinction between formal and material validity, the author addresses the problem of fitting the concept of material competence into one of the two categories, as well as the similarities and differences between statements of material validity and material competence.

Key words: legal validity, formal validity, material validity, substantive validity, material competence. 


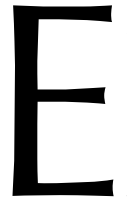

$\mathrm{n}$ este trabajo analizo tres nociones que son usualmente utilizadas por los juristas cuando se ocupan del problema de la validez de las normas jurídicas. Se trata de las nociones de validez formal, de validez material o sustantiva y de competencia material. Tomaré como punto de partida los términos en los que los juristas trazan habitualmente la distinción entre validez formal y validez material. Partiendo de este marco conceptual, me ocuparé del problema del encaje de la competencia material. Sostendré que, aunque los juristas suelen considerar la competencia material como un problema de validez formal, hay razones suficientes para dar un tratamiento autónomo de los juicios de competencia material. También me ocuparé de las similitudes y diferencias entre los juicios de validez material y los de competencia material. Mantendré que tanto los juicios de validez material como los de competencia material presuponen la atribución de un significado a las disposiciones jurídicas que se enjuician; pero que, pese a esta semejanza, ambos tipos de juicios tienen una naturaleza distinta. Los juicios sobre la validez material se dirigen bien a determinar la compatibilidad entre el contenido proposicional de las disposiciones (o, lo que es lo mismo, a detectar antinomias o inconsistencias), o bien a establecer la compatibilidad entre el balance que subyace a la disposición y otros balances del sistema, por lo que en este tipo de juicio están implicadas cualesquiera razones que el sistema contemple y que sean aplicables al caso en cuestión. En cambio, sostendré que cuando se trata de emitir juicios sobre la competencia material las razones se hallan más circunscritas; defenderé que sólo son pertinentes aquellas razones, sustantivas o institucionales, que contribuyan a dotar de sentido a la institución cuya competencia se cuestiona.

\section{VALIDEZ FORMAL Y VALIDEZ MATERIAL: LOS TÉRMINOS USUALES DE LA DISTINCIÓN}

Aunque con una terminología que puede oscilar, los juristas acostumbran a diferenciar entre validez formal y validez material de los actos o de las normas jurídicas ${ }^{1}$. De manera que parece razonable situar el punto de partida de nuestra investigación en los términos en los que usualmente dogmáticos y teóricos del Derecho emplean tal distinción. La validez formal o existencia ${ }^{2}$ suele vincularse al cumplimiento de una serie de requisitos relativos a las formas y procedimientos para la producción de resultados institucionales, así como a la competencia del órgano del que emanan. En cambio, la validez material o sustantiva se dice que depende de que el contenido del acto o la norma sea compatible con lo dispuesto en normas superiores ${ }^{3}$. Por tanto, los juicios de va-

\footnotetext{
${ }^{1}$ Antes de iniciar mi análisis, debo aclarar que, aunque de lo que me ocupo a lo largo de estas páginas es de las nociones de validez formal y material que predicamos de las normas jurídicas, buena parte de las conclusiones que sostengo son perfectamente extrapolables a los actos jurídicos.

2 En otro trabajo he argumentado en contra de esta equiparación entre validez formal y existencia [C $f r$. RÓDENAS, 2006: «Sobre la validez jurídica: entre la normatividad y la convención», Analisi e diritto, Milán: Giappichelli, pp. 249 a 270]. En breve volveré a referirme a los problemas que plantea dicha equiparación.

3 Sobre esta distinción $c f r$., entre otros, los trabajos de: FERRAJOLI, 1989: Derecho y razón, Madrid: Trotta, p. 874; GuASTINI, 1993: Le fonti del diritto e l'interpretazione, Milán: Giufrè, pp. 52 y ss.; AGUILÓ, 2000: Teoría general de las fuentes del Derecho ( $y$ del orden jurídico), Madrid: Ariel, pp. 78 y s.; DELGADO ECHEVERRíA, 2005: «El concepto de validez de los actos jurídicos de Derecho privado», Anuario de Derecho civil, núm. LVIII-1, enero de 2005, pp. 17 y ss. (cito por la versión digital).
} 
lidez formal y de validez material no estarían referidos exactamente al mismo objeto. La validez formal se predicaría del acto que da lugar al resultado normativo, mientras que la validez material afectaría al contenido de tal resultado ${ }^{4}$.

Usualmente los juristas trazan la distinción entre la validez formal y material apelando a la diferente respuesta que el ordenamiento jurídico imputa a los respectivos vicios de validez. Puesto que la validez formal se predica de los actos; mientras que la validez material se predica de los contenidos de los resultados de tales actos, la consecuencia jurídica de los vicios formales sería la inexistencia de tal acto y la de los materiales la nulidad ${ }^{5}$. De modo que, en el primer caso, el ordenamiento daría por no producido el resultado institucional; mientras que, en el segundo, el resultado se daría por producido (existente), aunque éste sería irregular. Pero, en mi opinión, éste es un mal criterio para aplicar a la distinción entre validez formal y material. En otro trabajo he tratado de mostrar que no toda vulneración de las exigencias formales que figuran en las normas que confieren poder supone sin más la inexistencia del resultado institucional. El incumplimiento de un mismo requisito formal puede dar lugar, según los casos, a la inexistencia del resultado, o simplemente a la irregularidad del mismo. Dicho en forma muy sintética, he sostenido que algunos vicios formales no llevan aparejada la inexistencia del acto, ya que el ordenamiento jurídico operaría con una especie de presunción favorable a la existencia; en tales casos hablaríamos con todo el sentido de resultados normativos existentes, aunque irregulares por vicios formales $^{6}$.

También es frecuente que se intente trazar la distinción entre la validez formal y material apelando a la diferente naturaleza de los respectivos juicios de validez. Así, se dice que la verdad de los juicios de validez formal es predicable sobre la base de simples averiguaciones empíricas o de hechos, mientras que los juicios de validez material requieren del desarrollo de una actividad interpretativa más compleja que involucra necesariamente juicios normativos. De manera que para emitir un juicio de validez formal bastaría con comprobar que se dan los hechos o actos que atribuyen la competencia y que el acto realizado por el sujeto es de la clase prevista en la norma de competencia; mientras que los juicios de validez material exigen comparar normas, es decir, enunciados normativos interpretados ${ }^{7}$.

Lo dicho hasta aquí reproduce lo que me parece que es un punto de vista ampliamente compartido por los juristas, pero disiento - al menos en parte- del mismo. En primer lugar, creo en algunos casos la determinación de la validez formal puede requerir de una actividad interpretativa considerablemente compleja que involucre valores jurídicos y requiera realizar balances entre principios, pero aquí me limitaré sólo a señalar esta cuestión, sin ocuparme de ella. En segundo lugar, pienso que los juicios de competencia material presentan peculiaridades propias que aconsejan un tratamiento distinto del resto de elementos que condicionan la validez formal. Es de este último aspecto del que me voy a ocupar en este trabajo.

\footnotetext{
Cfr. Guastini, 1993: p. 56, y Aguiló, 2000: p. 78.

5 Cfr. Ferrajoli, 1989: p. 874; Aguiló, 2000: pp. 78 y s., y Delgado Echevarría, 2005: p. 17.

${ }^{6}$ Cfr. RÓDENAS, 2006: pp. 249 a 270.

7 Cfr., entre otros, FerRajoli, 2000: p. 874, y Delgado Echevarría, 2005: p. 17.
} 


\section{EL PROBLEMA DE LA COMPETENCIA MATERIAL}

Hemos visto que la competencia material es uno de los elementos de los que usualmente los juristas consideran que depende la validez formal ${ }^{8}$. Sin embargo, los juicios relativos a la concurrencia o no de este elemento presentan una peculiaridad importante que no se produce respecto del resto de elementos determinantes de la validez formal: cuando tratamos de determinar si un órgano es o no competente para la producción de ciertos contenidos normativos nos resulta necesario atribuir un significado a las disposiciones que los expresan; al igual que cuando juzgamos la validez material de una norma, la identificación del vicio de competencia presupone la interpretación de la fuente en cuestión ${ }^{9}$. Así, tanto para poder afirmar que el decreto D del gobierno excede su competencia material, como para mantener que la ley $\mathrm{L}$ del parlamento es incompatible con el contenido de la constitución, es necesario interpretar el contenido de una fuente jurídica.

Una consecuencia importante que se sigue de lo anterior es que — como señala Riccardo GUASTINI — cuando una fuente pueda contener — como habitualmente sucedeuna gran cantidad de normas, bien puede ser que no todas ellas estén en contradicción con normas jurídicas superiores, o que no todas excedan de la competencia material para dictar la norma en cuestión. En tal caso, la invalidez no afecta a la fuente en su conjunto, sino que se limita a aquellas normas que sean incompatibles con normas jerárquicamente superiores o que disciplinen objetos reservados a otro tipo de fuente ${ }^{10}$.

Pero esta semejanza entre la competencia material y la validez material no nos puede llevar a confundir uno y otro tipo de juicios. La distinción entre estas dos nociones no es nada sencilla de trazar y profundizar en ella me va a llevar el resto de páginas de este trabajo. Podríamos tomar como punto de partida un hecho bastante evidente. La interpretación que se lleva a cabo cuando se trata de determinar la competencia material no desciende a juzgar la compatibilidad del contenido de la norma con el de otras normas superiores del sistema - como sucede cuando nos preocupa la validez material de la norma-, sino que sólo se preocupa de si el órgano en cuestión es competente para emitir una norma respecto de la materia de que se trate — con independencia de que su contenido sea acorde o no con otras normas del sistema-. Por el contrario, juzgar la compatibilidad del contenido de la norma con otras normas de rango superior es la tarea interpretativa que procede cuando cuestionamos la validez material o sustancial de una norma. Siguiendo a GUASTINI ${ }^{11}$ podríamos afirmar que, mientras que al hablar de la competencia material aludimos al objeto mismo de disciplina; al hablar de validez material nos referimos a cómo en una determinada fuente se disciplina una determinada materia ${ }^{12}$.

${ }^{8}$ Cfr. FerRajoli, 1989: p. 874, y Delgado EchevarRía, 2005: p. 17.

9 Guastini, 1993: p. 58.

${ }^{10}$ Guastin, 1993: p. 58.

${ }^{11}$ GuAstini, 1993: p. 57.

${ }^{12}$ Esta contraposición está también presente cuando ATIENZA y RUIZ MANERO realizan la siguiente estipulación: «Parece, pues, conveniente reservar el término materia para hacer referencia a aquéllo (a aquella porción del mundo) sobre la que se legisla y contenido para hacer referencia al significado del texto mediante el que se legisla» [cfr. «Seis acotaciones preliminares para una teoría de la validez jurídica...», Doxa. Cuadernos de Filosofía del Derecho, núm. 26, 2003, p. 724. 
Estas dificultades para encajar la competencia material entre los elementos integrantes de la validez formal, aconsejan — como propone GUASTINI — tratar la competencia material como una categoría autónoma, que no puede ser reconducida ni a la de validez formal ni a la validez material ${ }^{13}$. De manera que, una norma autonómica en materia penal podría ser válida desde el punto de vista de los criterios de validez formal (si hubiera sido aprobada por el parlamento autonómico, de acuerdo con el procedimiento establecido al respecto) y también válida desde el punto de vista de los criterios de validez material (siempre que su contenido no contradijera ninguna norma de rango superior) pero, sin embargo, ser finalmente inválida porque la competencia legislativa de las comunidades autónomas no comprende la materia penal (las comunidades autónomas no son competentes para legislar en materia penal).

En lo que sigue voy a profundizar algo más en los juicios de competencia material, siguiendo para ello una estrategia de aproximación en dos pasos: en primer término voy a indagar cuál es la naturaleza de la tarea interpretativa que llevamos a cabo cuando formulamos juicios de validez material para, una vez esclarecida esta cuestión, plantearme en la siguiente sección cuáles son las características propias de juicios de competencia material y en qué difieren de los juicios de validez material.

\section{LOS JUICIOS DE VALIDEZ MATERIAL O SUSTANTIVA}

Empecemos pues indagando sobre la naturaleza de la tarea interpretativa que llevamos a cabo cuando formulamos juicios de validez material. Volviendo nuevamente a la caracterización que usualmente hacen los juristas de los juicios de validez material, se recordará que éstos suelen entender que tales juicios se refieren a la compatibilidad del contenido de las disposiciones con lo dispuesto en normas superiores. Pero esta caracterización de la validez material es demasiado elemental, por lo que se hace indispensable tratar de profundizar algo más en la noción. Concretamente quiero mostrar que resulta empobrecedor entender que los juicios de validez material se reducen a determinar la compatibilidad del contenido proposicional de una norma con el de otra norma de rango superior ${ }^{14}$. Ciertamente, el supuesto más obvio de invalidez material es el que se produce por la inconsistencia entre el contenido proposicional de las normas. Esta inconsistencia puede revestir la forma de cualquiera de las antinomias de primer grado a las que se refería Ross: total-total; total-parcial y parcial-parcial.

Ahora bien, en el Derecho pueden presentarse también problemas de coherencia normativa que no encajan en ninguna de las categorías anteriores y que, no obstante, afectan a la validez material de las normas. Vincular la validez material o sustantiva a la coherencia normativa supone adoptar una visión del Derecho amplia, en la que éste no se concibe únicamente como un mecanismo que tiene la función de proporcionar una guía estable de la conducta, mediante el establecimiento unívoco de cuáles son nuestros deberes. Además, es necesario que concibamos al Derecho como una forma de pro-

\footnotetext{
13 GuASTINI, 1993: p. 57.

14 Guastini, 1993: p. 56.
} 
tección de un conjunto más o menos ordenado de bienes o valores que el ordenamiento incorpora ${ }^{15}$.

Por supuesto, no estoy hablando sólo del reconocimiento por parte del Derecho de una serie de valores o principios. La alusión a valores o principios en los textos constitucionales; tratados internacionales; exposiciones de motivos de las leyes; resolución judicial de disputas; etc., es algo a lo que estamos completamente habituados. Lo que a menudo no nos resulta tan obvio es que el Derecho, junto con el reconocimiento de valores o principios, también establece prioridades entre ellos o - si se prefiere- realiza ponderaciones. Estos balances entre razones pueden ser introducidos expresamente por el constituyente o el legislador, o ser el resultado de la reconstrucción consolidada por parte de los órganos de aplicación de los materiales emitidos por aquellos; pueden afectar a todo un sector o subsector del ordenamiento jurídico, o simplemente a la regulación de casos determinados contemplados genéricamente en las reglas regulativas.

Lo que tienen en común todas estas situaciones es que son manifestaciones de cómo en el desarrollo del Derecho se va construyendo la estructura de un edificio en la que los resultados de las ponderaciones entre razones se nos presenta de forma ordenada ${ }^{16}$. Quiere decirse que el Derecho no sólo se nos presenta con una pretensión de guía unitaria de la conducta, sino también como una forma de protección de un conjunto más o menos estable, ordenado y coherente de valores. Donde más claramente percibimos este aspecto bifronte del Derecho es cuando descendemos a analizar la naturaleza de las reglas regulativas: Acostumbramos a ver las reglas regulativas como meros mecanismos de guía de la conducta pero, eventualmente, puede ser necesario adentrarnos también en la justificación que subyace a las mismas, lo que no es diferente de preguntarnos cuál es el balance de razones subyacente a las mismas. Cuando circulo con mi coche y observo una señal de tráfico que prohíbe la entrada de vehículos a un parque, no suelo plantearme cuál es la razón subyacente a esta prohibición; puedo atribuir significado a una señal de tráfico que me prohíbe circular por una calle sin necesidad de esclarecer cuál es la razón que ha llevado a tal prohibición. A este fenómeno se le conoce como autonomía semántica de los enunciados normativos en relación con su justificación subyacente ${ }^{17}$. Esta autonomía semántica no excluye, claro está, que cuando se produce un desajuste entre uno y otro nivel de las normas sea preciso recurrir a las razones subyacentes a una regla para excepcionar o limitar el alcance de su contenido proposicional ${ }^{18}$. Ahora bien, estas son operaciones que condicionan la aplicabilidad de una norma, pero que en nada cuestionan su validez.

Así pues, aunque no siempre es posible, por lo común en el Derecho podemos diferenciar dos niveles en relación con una misma regla regulativa: el de su contenido pro-

${ }^{15}$ Sobre estas dos funciones del Derecho y su vinculación las exigencias de consistencia y coherencia, $c f r$. Aguiló, 2000: pp. 95 y 96.

${ }^{16}$ Esta idea de orden no puede interpretarse como la correspondencia con un proyecto inicial perfectamente definido, por el contrario, la propia práctica va introduciendo modificaciones en la arquitectura del edificio.

${ }_{17}$ Cfr. SCHauer, 1991: Playing by the Rules, Oxford Clarendon Press.

${ }^{18}$ Me he ocupado con detalle de las nociones de excepción y de límite al alcance de una norma en «En la penumbra: Indeterminación, derrotabilidad y aplicación judicial del Derecho», Doxa. Cuadernos de filosofía del Derecho, núm. 24, 2001, pp. 63 a 84 y en «¿Qué queda del positivismo jurídico?», Doxa. Cuadernos de Filosofía del Derecho, núm. 26, 2003, pp. 417 a 448. 
posicional y el de su justificación subyacente. Por lo general, vamos a poder determinar cuál es el contenido proposicional de una norma sin necesidad de esclarecer cuál es su justificación subyacente. También sabemos que los desajustes entre ambos niveles de las normas se salvan exceptuando o limitando el alcance del contenido proposicional de las normas. Pero este esquema es todavía demasiado sencillo y aún no es capaz de dar cuenta de los problemas de validez material de los que ahora pretendo ocuparme.

La cuestión que deseo suscitar es la siguiente: Si hay ocasiones en las que el Derecho requiere que pasemos por alto el contenido proposicional de las disposiciones y establezcamos excepciones o límites en su alcance, ¿puede suceder otro tanto en relación al balance de razones subyacente a las mismas?; ¿puede el Derecho obligarnos a cuestionarnos el balance de razones subyacentes a una norma? La respuesta a esta cuestión, en mi opinión, debe ser claramente afirmativa. Debemos cuestionarnos el balance entre razones subyacente a una norma siempre que su resultado esté en contradicción con el que arroja el balance subyacente a otra norma que sea aplicable al mismo caso genérico; o con balances subyacentes al sector o subsector del ordenamiento al que pertenece la norma; o con balances característicos de la institución que regula; etc. Todos estos supuestos no son sino manifestaciones de problemas de coherencia normativa que afectan a la validez material.

En suma, el Derecho presenta la doble dimensión de guía unitaria de la conducta y de protección de un conjunto más o menos ordenado de valores. Sabemos que la función de guía unitaria de la conducta se ve cuestionada cuando dos o más normas son aplicables a un mismo caso y presentan soluciones normativas incompatibles entre sí, pero algo semejante puede suceder en relación con la función de protección de valores. En esta última dimensión del Derecho los problemas aflorarán cuando sea aplicable a un mismo supuesto de hecho más de un balance entre razones procedentes del mismo sistema. Concretamente, mi propuesta es interpretar los problemas de coherencia normativa que afectan a la validez material de las normas en clave de desajustes entre la justificación subyacente a las normas y otras ponderaciones que forman parte del Derecho. Por tanto, no cabe una aprehensión exhaustiva del problema de la validez material sin dar cuenta de estos desajustes que se producen en el nivel de las razones subyacentes a las normas.

En el siguiente cuadro trato de sintetizar las principales conclusiones que arroja mi análisis anterior sobre los juicios de validez material:

Juicios de validez material

\begin{tabular}{|c|c|c|}
\hline $\begin{array}{c}\text { Tipo de vicio } \\
\text { detectado }\end{array}$ & $\begin{array}{c}\text { Antinomia } \\
\text { o inconsistencia }\end{array}$ & $\begin{array}{c}\text { Incoherencia normativa } \\
\text { o incongruencia }\end{array}$ \\
\hline $\begin{array}{c}\text { Nivel del Derecho } \\
\text { en que se manifiesta }\end{array}$ & $\begin{array}{c}\text { Contenidos proposicionales } \\
\text { de las normas }\end{array}$ & $\begin{array}{c}\text { Compromisos entre razones } \\
\text { subyacentes a las normas }\end{array}$ \\
\hline $\begin{array}{c}\text { Función del Derecho } \\
\text { afectada }\end{array}$ & Guía unitaria de la conducta & $\begin{array}{c}\text { Protección de un conjunto } \\
\text { ordenado de valores }\end{array}$ \\
\hline
\end{tabular}




\section{LOS JUICIOS DE COMPETENCIA MATERIAL}

Esta reflexión sobre los juicios de validez material nos abona el camino para profundizar algo más en los juicios de competencia material. Sabemos que tanto en los juicios de validez material como en los de competencia material es necesario atribuir un significado a las disposiciones jurídicas que se enjuician; pero que, pese a esta semejanza, la naturaleza de la actividad interpretativa que se lleva a cabo en ambos tipos de juicios es distinta. Como acabamos de ver, los juicios de validez material se dirigen bien a determinar la compatibilidad entre el contenido proposicional de las disposiciones (o, lo que es lo mismo, a detectar antinomias o contradicciones), o bien a establecer la compatibilidad entre el balance que subyace a la disposición y otros balances del sistema. La naturaleza de los juicios de competencia material es diferente. El objeto de esta sección va a ser abordar de forma directa las características propias de juicios de competencia material.

\subsection{A los conflictos de competencia material subyace una controversia en torno a la distribución de poder normativo}

Los conflictos de competencia material involucran a dos (o más) entidades jurídicas dotadas de poder político. Se trata de entidades con capacidad de alterar la situación normativa de los sujetos; pueden modificar, como resultado del ejercicio de una potestad legislativa, reglamentaria o administrativa, el conjunto de derechos y obligaciones de los individuos a ellas sometidos. Dichas entidades compiten entre sí por el ejercicio del poder político en una cierta materia. El resultado de la competición es el característico de los llamados «juegos de suma cero»: en la medida en la que una de las entidades atrae hacia sí la competencia material objeto de la disputa, disminuye el poder político de la otra.

Sería forzado hablar de conflictos de competencia material en situaciones en las que no están confrontadas dos entidades jurídicas que rivalizan entre sí por el ejercicio del poder político: Cuando los involucrados son simplemente una entidad jurídica, de un lado, y los sujetos a ella sometidos, de otro, los sujetos individuales que se oponen al ejercicio del poder político por parte de la entidad jurídica apelan directamente a principios jurídicos fundados en el valor sustantivo de la autonomía individual. En suma, en este segundo supuesto parece más lógico entender que lo que se está cuestionando es la validez material o sustantiva del acto o resultado normativo.

\subsection{El filtro institucional de las razones implicadas}

La segunda cuestión que parece imprescindible tratar de esclarecer es la de cuáles son las razones pertinentes para fundar un juicio sobre la competencia material. Tanto en la determinación de la competencia material como en la de la validez sustantiva puede ser necesario llevar a cabo una tarea interpretativa que involucre a principios sus- 
tantivos e institucionales ${ }^{19}$ y que requiera de la realización de juicios de ponderación, por lo que no puede ser éste el criterio de distinción entre uno y otro tipo de juicio. La diferencia concierne más bien cuáles son las razones pertinentes para fundar ambos tipos de juicios: En el caso de los juicios sobre la competencia material las razones se hagan más circunscritas que en los de validez material o sustantiva; sólo son pertinentes aquellas razones, sustantivas o institucionales, que contribuyan a dotar de sentido a la institución cuya competencia se cuestiona.

En suma, podríamos decir que las razones que se toman como base para la resolución de la controversia deberán haber pasado por una suerte de filtro institucional. Dicho filtro institucional atañe directamente al fin o sentido por el que se atribuye una competencia a una determinada entidad jurídica, pero también comprendería, en un sentido más amplio, consideraciones relativas al encaje de la entidad en el conjunto del entramado institucional en el que se desenvuelve. Ambos tipos de consideraciones - las relativas al fin propio de la entidad y las que concernientes al encaje institucional de la entidad - se entretejerían formando un filtro institucional por el que debe pasar toda razón que se pretenda relevante para la resolución de la controversia sobre la competencia material.

\subsection{Una tipología de conflictos materiales de competencia}

Naturalmente, el fin o sentido de las entidades jurídicas dotadas de poder político tiene un carácter predominantemente histórico y contingente, lo que dificulta su abordaje desde la teoría general del Derecho; el esclarecimiento del fin o funciones de tales entidades es una tarea reservada, en una amplia medida, a las diversas ramas de la (alta) dogmática jurídica, y de forma muy significativa al Derecho constitucional y administrativo. No obstante, sin necesidad descender al grado de concreción con el que la dogmática jurídica se ocupa de estas cuestiones, todavía es posible trazar en un nivel bastante abstracto una tipología genérica de los conflictos de competencia material que arroje alguna luz sobre la cuestión.

\subsubsection{Conflictos borizontales de competencia}

Generalmente, cuando se habla de conflictos de competencia material suele pensarse en conflictos entre entidades no articuladas jerárquicamente entre sí, lo que su-

${ }^{19}$ Sobre la distinción entre razones sustantivas y razones institucionales $c f$. ATIENZA y RUIZ MANERO: Las piezas del Derecho, 2004, Barcelona, Ariel, pp. 27 a 28. Las razones institucionales suelen contraponerse a las sustantivas. Estas últimas consistirían en un conjunto de valores u objetivos colectivos relativos al modelo de convivencia entre los seres humanos que el Derecho pretende alcanzar. Por el contrario, la razones institucionales constituirían un conjunto de valores internos al Derecho, relacionados centralmente con su buen funcionamiento, eficiencia y eficacia. Aunque una categoría se contraponga a la otra y, en ocasiones, pueda existir una tensión entre lo que exigen ambos tipos de razones, muchas razones institucionales no son sino la plasmación, de cara al funcionamiento interno del Derecho, de razones sustantivas: por ejemplo, el principio de legalidad sería una traducción a la esfera interna del Derecho del principio sustantivo de autonomía personal. Por otro lado, una característica importante de las razones institucionales, y que conviene tener presente, es que éstas, a diferencia de las sustantivas, no precisan ser universalizables. Por ejemplo, valores como la preservación de la monarquía o la autonomía municipal son relativos sólo a ciertas prácticas jurídicas. Y algo parecido sucede con otras tantas razones instituciones que traen su causa en la historia. Se trataría, en suma, de valores que sólo contarían en relación determinadas prácticas. 
pone que las disposiciones dictadas por cada una de ellas no son jerárquicamente superiores ni inferiores a las dictadas por la otra ${ }^{20}$. A este tipo de conflicto de competencia podríamos llamarlo conflicto horizontal de competencia. Quizás convenga aclarar que en los conflictos horizontales puede (y suele) existir una distribución vertical del poder político; esto es lo que sucede en España respecto del Estado y las Comunidades Autónomas ${ }^{21}$. Lo relevante es que, dentro de su propio ámbito competencial, cada órgano ostenta un poder autónomo y excluyente. Así, como señalan GARCÍA DE ENTERRÍA y Tomás-Ramón FERNÁNDEZ, dentro de su propio ámbito autonómico, constitucional o legalmente establecido, las normas autonómicas son supremas y excluyen a las normas de cualquier otro ordenamiento, las cuales, lejos de poder pretender en dicho ámbito cualquier superioridad por su origen diverso, serán nulas por invadir la esfera garantizada al principio autonómico ${ }^{22}$.

Para la resolución de este tipo de controversias no es de aplicación el principio de jerarquía normativa; en su lugar los dogmáticos hacen referencia al «principio general de separación» 0 «principio de la competencia» ${ }^{23}$. Pero este principio no tiene ningún contenido normativo material y no expresa exigencias relativas a valores sustantivos; se trata más bien de lo que podríamos llamar una metanorma interpretativa. El principio viene a decir algo tan sencillo (e impreciso) como que para la resolución de conflictos de competencia se estará a las razones instituciones que están en la base del reparto competencial; excluyendo cualquier otra razón (sustantiva o institucional) que, aunque forme parte del sistema jurídico, no guarde relación con la función de la distribución de la competencia. Se trata, por lo tanto, de un criterio interpretativo que obliga a seleccionar unas razones y a excluir otras del conjunto de razones sobre cuya base se adopta la resolución. En realidad el principio de la competencia no es más que la técnica de la que el ordenamiento jurídico se vale para entretejer el filtro institucional al que he hecho alusión más arriba. Por ejemplo, en el caso de los conflictos de competencia entre el Estado y las Comunidades Autónomas, razones como el interés general, el derecho a unas prestaciones minimas comunes de los administrados, o el derecho de participación, son comúnmente aceptadas como base sobre la que fundar la solución del caso ${ }^{24}$.

Por supuesto, será la práctica argumentativa de los tribunales y a la labor reconstructiva de la dogmática jurídica quienes doten de contenido al principio ${ }^{25}$. Pero lo que sí puede hacer la teoría del Derecho es proporcionar el marco teórico y el instrumental analítico necesarios para emprender esta tarea.

${ }^{20}$ Cfr. García de Enterría y FernándeZ, 2002: Curso de Derecho administrativol, Madrid: Civitas, p. 284.

${ }^{21}$ Cfr. STC 32/1981, fundamento jurídico 3. ${ }^{\circ}$

${ }^{22}$ Cfr. GARCÍA DE ENTERRÍA y FERNÁNDEZ, 2002: p. 284. Salvo que se trate de una norma que tenga rango suficiente para modificar, o incluso suprimir, dicha esfera o ámbito, ob. cit., p. 284.

${ }^{23}$ Cfr. GARCía de EnTERRía y FernáNDEZ, 2002: ob. cit., pp. 74 y 284 y ss.

${ }^{24}$ Cfr. STC 32/1981, fundamento $5 .^{\circ}$

25 En relación con los conflictos de competencia entre el Estado y las Comunidades Autónomas, E. GARCÍA DE ENTERRÍA y T.-R. FERNÁNDEZ señalan que la «normación básica» que se atribuye al Estado «ha de integrar tres elementos distintos, articulados entre sí a modo de tres sucesivos círculos concéntricos, de menor a mayor»: el «círculo del interés general»; el «círculo del encuadramiento», y el «círculo de la suplencia», 2002: pp. 301 y ss. 


\subsubsection{Conflictos verticales de competencia}

No todos los conflictos de competencia conciernen a entidades jurídicas entre cuyas fuentes no hay subordinación jerárquica; también es posible que se produzcan conflictos de competencia entre entidades cuyas fuentes se hallan subordinadas entre $\mathrm{si}^{26}$. Esta última posibilidad, que parece chocar con principios tan consustanciales al Derecho como el principio de jerarquía normativa o de deferencia al legislador es, sin embargo, comúnmente aceptada en la práctica por los tribunales, aunque - como vamos a ver- dentro de unos límites bastante restringidos.

Es común apelar a la idea de garantía institucional constitucional para hacer valer un reducto indisponible o núcleo esencial de las instituciones que la Constitución garantiza y que no puede ser rebasado por el legislador. La garantía institucional constituye un recurso jurisprudencial concebido como garantía frente a los abusos y excesos del órgano que ocupa un nivel superior en los conflictos de competencia verticales. El principio opera como una garantía de los elementos imprescindibles constitutivos del núcleo esencial de la institución constitucionalmente garantizada. Pero antes de emprender un análisis más minucioso de la idea de la garantía institucional, merece la pena que recapitular los aspectos centrales que llevamos vistos. En el siguiente cuadro se resumen los dos tipos de conflictos de competencia material a los que he hecho alusión, así como los principales técnicas a las que se recurre para su resolución:

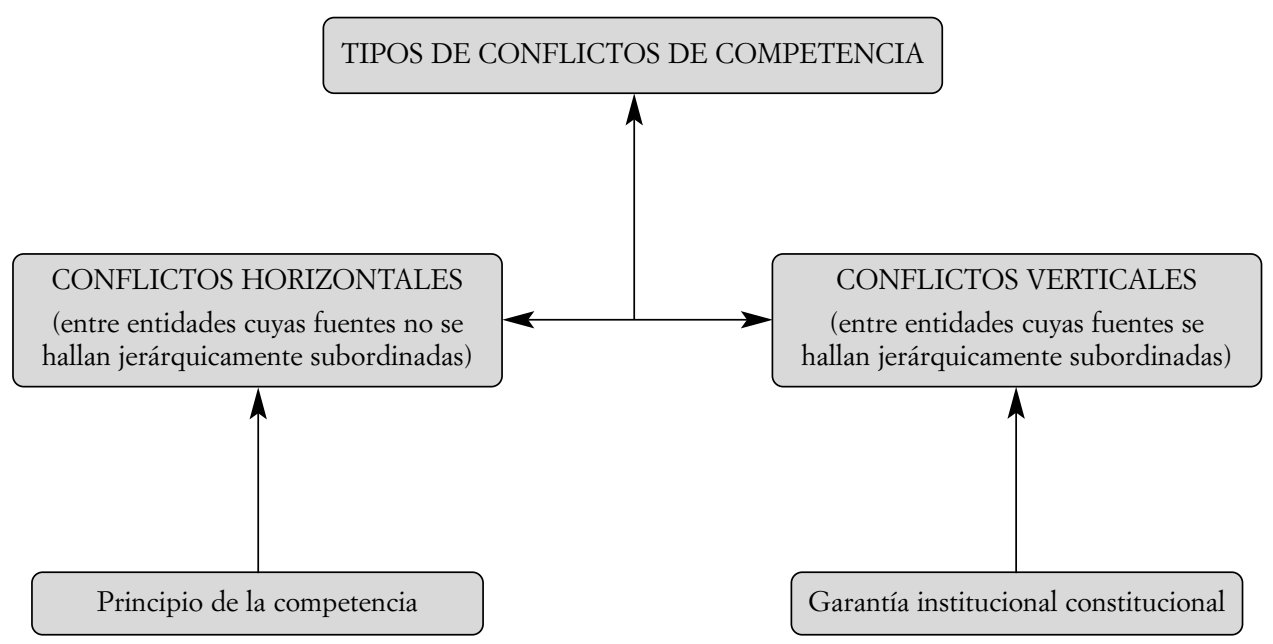

${ }^{26}$ A este respecto se hace indispensable introducir aquí una precisión terminológica: Los juristas acostumbran a reservar el término conflicto de competencias para referirse a lo que aquí he denominado conflicto borizontal de competencias. La razón de ello es que —al menos en el ordenamiento jurídico español— el cauce procesal por el que se dirimen los conflictos horizontales es un cauce específico que precisamente recibe el nombre de conflicto constitucional de competencia (positiva). 


\subsection{Algo más sobre la garantía institucional}

Como acabo de indicar, nuestro recorrido por las razones en las que se fundan los juicios de competencia material parece exigir llevemos a cabo un examen más minucioso de la garantía institucional.

\subsubsection{Un breve recorrido jurisprudencial}

Veamos, para empezar, algunos ejemplos en los que se apela a dicha técnica con el objeto de recortar la competencia del órgano que ocupa una posición dominante:

En la sentencia 32/1981 el Tribunal Constitucional español declaró inconstitucional la ley autonómica catalana que transfería a la Generalitat la totalidad de competencias otorgadas por el ordenamiento vigente a las Diputaciones de las cuatro provinciales catalanas, señalando que:

«El orden jurídico-político establecido por la Constitución asegura la existencia de determinadas instituciones, a las que se considera como componentes esenciales y cuya preservación se juzga indispensable para asegurar los principios constitucionales, estableciendo en ellas un núcleo o reducto indispensable por el legislador. Las instituciones garantizadas son elementos arquitecturales indispensables del orden constitucional y las normaciones que las protegen son, sin duda, normaciones organizativas, pero a diferencia de lo que sucede con las instituciones supremas del Estado, cuya regulación orgánica se hace en el propio texto constitucional, en éstas la configuración institucional concreta se defiere al legislador ordinario, al que no se fija más límite que el del reducto indisponible o núcleo esencial de la institución que la Constitución garantiza. Por definición, en consecuencia, la garantía institucional no asegura un contenido concreto o un ámbito competencial determinado y fijado de una vez por todas, sino la preservación de una institución en términos recognoscibles para la imagen que de la misma tiene la conciencia social en cada tiempo y lugar. Dicha garantía es desconocida cuando la institución es limitada, de tal modo que se la priva prácticamente de sus posibilidades de existencia real como institución para convertirse en un simple nombre. Tales son los límites para su determinación por las normas que la regulan y por la aplicación que se haga de éstas. En definitiva, la única interdicción claramente discernible es la de la ruptura clara y neta con esa imagen comúnmente aceptada de la institución que, en cuanto formación jurídica, viene determinada en buena parte por las normas que en cada momento la regulan y la aplicación que de las mismas se hace» ${ }^{27}$.

De forma análoga, en la sentencia C-351/04 de la Corte Constitucional de Colombia se da la razón la Comisión Nacional de Televisión, frente las injerencias de Ministerio de Comunicaciones, recurriendo a esta misma idea de la garantía institucional constitucional:

«[L]a autonomía de la Comisión Nacional de Televisión es lo que podría denominarse una "garantía institucional" del organismo, que le permite desarrollar sus funciones a salvo de presiones políticas y económicas y lejos de la influencia de los gobiernos de turno. La garantía institucional de la autonomía de la Comisión Nacional de Televisión, que le asegura el aislamiento de las fuentes de presión política y económica, abriga el derecho de la sociedad a que la televisión no sea controlada por grupos de interés, ofreciéndose a todos de manera independiente, democrática y pluralista. En este sentido, la autonomía representa para

${ }^{27}$ El énfasis es mío. 
la Comisión Nacional de Televisión un rasgo mínimo de su naturaleza institucional, sin el cual no le sería posible desarrollar a plenitud su objeto jurídico» ${ }^{28}$.

\subsubsection{La garantía institucional como metanorma interpretativa}

Una primera consideración a tener en cuenta es que, al igual que sucedía con el principio de la competencia, la garantía institucional puede ser caracterizada también como una metanorma interpretativa: Tampoco este criterio prescribe ningún contenido normativo material o sustantivo, sino que más bien orienta la labor de los tribunales en el manejo de las razones aplicables al caso, dirimiendo la preferencia entre diversos criterios de solución concurrentes. Ahora bien, a diferencia del principio de competencia, la garantía institucional no obliga al aplicador del Derecho a excluir ciertas razones del conjunto de principios que sirven de base para la decisión; la garantía institucional obliga a los tribunales a fijar un cierto límite mínimo institucional que el legislador ordinario no puede traspasar y, en el supuesto de que tal límite haya sido traspasado, a bloquear el peso de otras razones que en principio debieran de servir como fundamento de la decisión - como el principio de jerarquía normativa o de deferencia al legislador-. Dicho en otros términos, cuando el órgano superior se extralimita en la autoatribución de su competencia, la metanorma interpretativa de la garantía institucional opera como un mecanismo de inhibición del peso de los principios aplicables a la controversia.

Como ya he indicado, la garantía institucional es un recurso jurisprudencial concebido como garantía frente a los abusos y excesos del órgano que ocupa un nivel superior en los conflictos de competencia verticales, pero hay dos matices deben ser introducidos aquí. En primer lugar, por hipótesis la garantía institucional funciona bidireccionalmente: Puede operar también en el otro sentido, favoreciendo al órgano jerárquicamente superior ${ }^{29}$. La otra consideración es que la garantía puede operar también en los conflictos horizontales. Aunque, como acabamos de ver, los conflictos horizontales se gobiernan por el principio de la competencia, siempre que el exceso en la arrogación de competencia por parte de un órgano ponga en peligro la subsistencia del otro será necesario echar mano de la garantía institucional para resolver la controversia. En realidad no me parece que haya mayor dificultad en invocar simultáneamente ambos principios para resolver un mismo problema de competencia: La garantía institucional es una consideración más que puede ser necesario tener en cuenta cuando nos preguntamos por el fin o sentido de las atribución de la competencia; de ahí que pase sin mayor dificultad el filtro institucional impuesto por el principio de la competencia.

\subsubsection{La extensión de la garantía institucional}

Pero, sin lugar a dudas, la cuestión más interesante y más polémica que suscita la idea de la garantía institucional es la de hasta dónde se extiende la garantía institucio-

\footnotetext{
${ }^{28}$ El énfasis es mío.

${ }^{29}$ Cfr. García de EnTERría y FernándeZ, 2002: p. 286.
} 
nal. Ésta es una cuestión extremadamente compleja por las profundas consideraciones políticas implicadas. Al menos en lo que a los conflictos verticales de competencia se refiere - que recordemos que constituyen el ámbito natural en el que se desenvuelve la garantía institucional ${ }^{30}$ - la garantía compite siempre con el principio de deferencia al legislador y con el de separación de poderes. De acuerdo con tales principios, fuera de los estrictos límites constitucionales, el diseño institucional es una cuestión librada al legislador ordinario, sin que quepan intromisiones por parte de los jueces y tribunales.

El caso es que, cuando un tribunal estima que la privación de una competencia dificulta o imposibilita el cumplimiento de los fines de una entidad, debe llevar a cabo lo que podríamos llamar un juicio de adecuación o de eficacia institucional; la cuestión es dónde se sitúan los límites de tales juicios de adecuación o eficacia institucional. ¿Para que se active la garantía institucional es necesario que haya un riesgo real de que la institución desaparezca, o basta con que ésta pueda resultar ineficiente? Responder a esta cuestión nos exige reparar en que los juicios de adecuación o eficacia institucional pueden ser ordenados en una escala gradual; aunque no es posible reproducir dicha escala por completo, éstos sería algunos de los niveles más significativos que pueden ayudarnos a responder a la pregunta que tenemos pendiente:

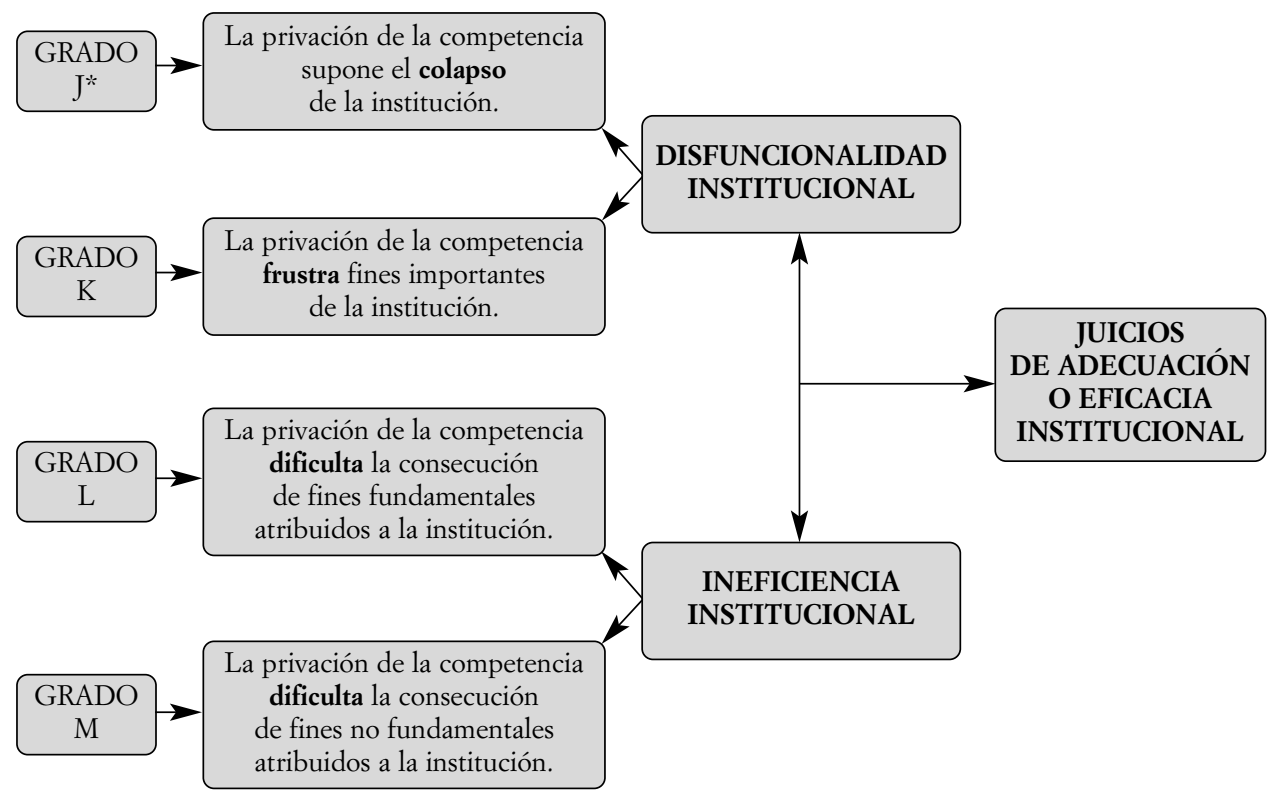

* Donde $\mathrm{J}>\mathrm{K}>\mathrm{L}>\mathrm{M}$.

${ }^{30}$ Como más adelante explicaré, en los conflictos de competencia material horizontales el meta principio institucional de deferencia al legislador se contrarresta, ya que, al no haber subordinación jerárquica respecto de la materia, el principio opera por igual del lado de los dos órganos confrontados. 
Una vez que hemos fijado esta serie de grados en la escala de los juicios de adecuación institucional, podemos ya tratar de responder a la pregunta anterior: La garantía institucional opera claramente en casos de disfuncionalidad institucional; esto es, tanto cuando existe peligro de que la institución se colapse (grado J), como cuando se frustran fines fundamentales de la institución (grado K). Pero conforme nos vamos alejando del grado $\mathrm{K}$-el fracaso de fines fundamentales de la institución- la garantía institucional va cediendo su espacio al principio de deferencia al legislador. Si la privación de la competencia dificulta la consecución de fines importantes atribuidos a la institución (grado L) resultará discutible que la garantía institucional pueda imponerse al principio de deferencia a legislador, y tanto más si tales fines no son fundamentales (grado - digamos- M).

Pero este análisis se circunscribe al ámbito de los conflictos verticales de competencia que - como ya he indicado- constituyen el ámbito natural en el que se desenvuelve la garantía institucional. En los conflictos de competencia horizontal las cosas son algo diferentes. En estos conflictos, al no haber subordinación jerárquica respecto de la materia, el principio de deferencia al legislador opera del lado de los dos órganos confrontados; por lo que podríamos decir que se contrarresta. Esto supone que, en aquellos supuestos en los que la garantía institucional sea aplicable a los conflictos de competencia horizontales, los juicios de adecuación o eficacia institucional puedan ser más exhaustivos y pueda más fácilmente oponerse la garantía cuando la privación de la competencia dificulte la consecución de fines importantes atribuidos a la institución (grado L) o incluso aún no tratándose de fines fundamentales (grado M).

En el siguiente cuadro se resume los aspectos centrales de lo que llevo dicho:

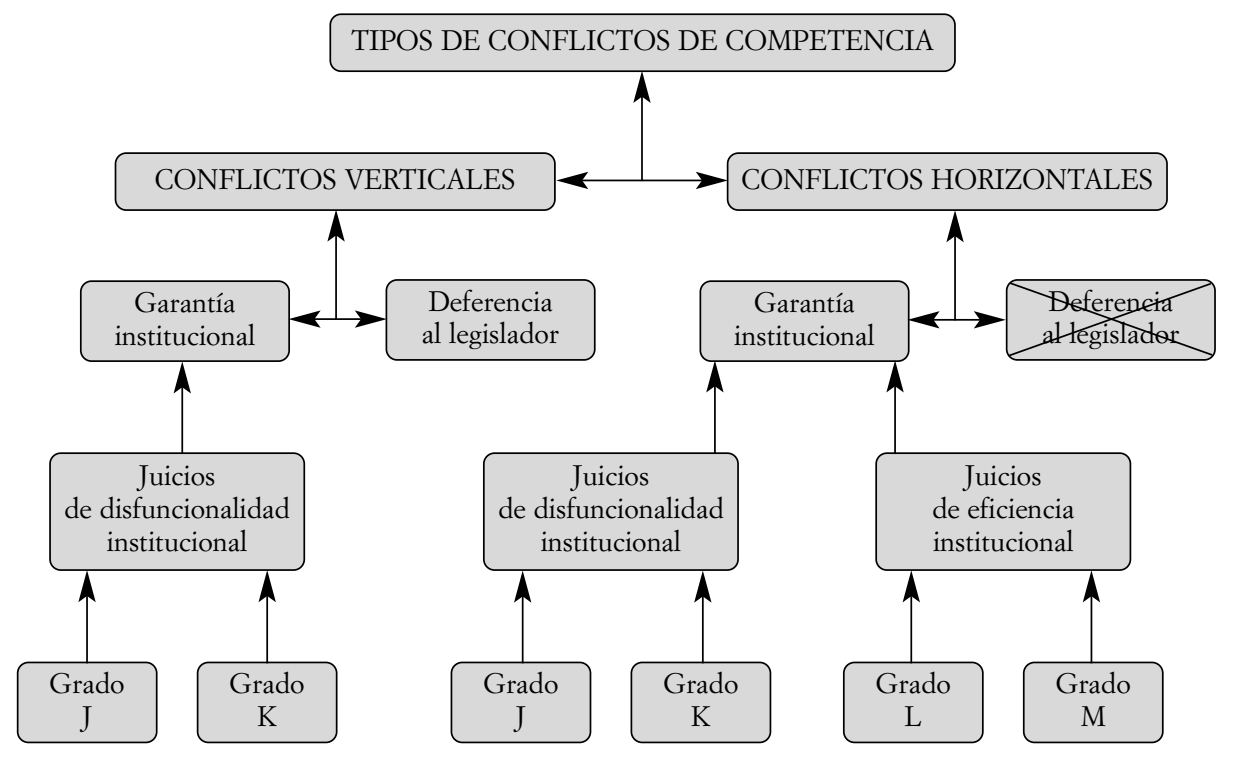




\section{CONCLUSIONES}

A continuación, a modo de resumen, voy a enumerar las principales conclusiones que se extraen de este trabajo:

1. He situado el punto de partida de este trabajo en los términos en los que usualmente dogmáticos y teóricos del Derecho emplean la distinción entre validez formal y validez material. He advertido también cómo los juicios referidos a la competencia material presentan características propias que aconsejan un tratamiento diferenciado respecto de los juicios de validez formal y material.

2. Tanto en la determinación de la competencia material como en la de la validez sustantiva puede ser necesario llevar a cabo una tarea interpretativa que involucre a principios sustantivos e institucionales y que requiera de la realización de juicios de ponderación, por lo que no puede ser éste el criterio de distinción entre uno y otro tipo de juicio. La actividad interpretativa que se lleva a cabo cuando se trata de emitir juicios de validez material se dirige bien a determinar la compatibilidad entre el contenido proposicional de las disposiciones (o, lo que es lo mismo, a detectar antinomias o contradicciones), o bien a establecer la compatibilidad entre el balance que subyace a la disposición y otros balances del sistema.

3. En los juicios sobre la competencia material las razones se hallan más circunscritas que en los de validez material o sustantiva; sólo son pertinentes aquellas razones, sustantivas o institucionales, que contribuyan a dotar de sentido a la institución cuya competencia se cuestiona. He sostenido que las razones que se toman como base para la resolución de la controversia deben pasar por una suerte de filtro institucional. Dicho filtro institucional atañe directamente al fin o sentido por el que se atribuye una competencia a una determinada entidad jurídica, pero también comprendería, en un sentido más amplio, consideraciones relativas al encaje de la entidad en el conjunto del entramado institucional en el que se desenvuelve.

4. Generalmente, cuando se habla de conflictos de competencia material suele pensarse en conflictos entre poderes normativos autónomos; entre los que no existe una subordinación jerárquica de sus disposiciones. He llamado a este tipo de conflicto conflictos horizontales de competencia. Para la resolución de este tipo de controversias no es de aplicación el principio de jerarquía normativa; en su lugar los dogmáticos hacen referencia al «principio de la competencia». Este principio constituye una metanorma interpretativa que viene a decir que para la resolución de conflictos de competencia se estará a las razones instituciones que están en la base del reparto competencial; excluyendo cualquier otra razón (sustantiva o institucional) que, aunque forme parte del sistema jurídico no guarde relación con la función de la distribución de la competencia. He sostenido que el principio de la competencia no es más que la técnica de la que el ordenamiento jurídico se vale para entretejer el filtro institucional al que he hecho alusión más arriba.

5. También es posible que se produzcan conflictos de competencia entre entidades cuyas disposiciones se hallan subordinadas entre sí. Es común apelar a la idea de garantía institucional constitucional para hacer valer un reducto indisponible o núcleo esencial de las instituciones que la Constitución garantiza y que no puede ser rebasado por el legislador. Al igual que sucedía con el principio de la competencia, la garantía 
institucional puede ser caracterizada también como una metanorma interpretativa. La garantía institucional obliga a los tribunales a fijar un cierto límite mínimo institucional que el legislador ordinario no puede traspasar y, en el supuesto de que tal límite haya sido traspasado, a bloquear el peso de otras razones que en principio debieran de servir como fundamento de la decisión — como el principio de jerarquía normativa o de deferencia al legislador.

6. La cuestión más interesante y más polémica que suscita la idea de la garantía institucional es la de hasta dónde se extiende esta garantía. Ésta es una cuestión extremadamente compleja por las profundas consideraciones políticas implicadas: al menos en lo que a los conflictos verticales de competencia se refiere - que constituyen el ámbito natural en el que se desenvuelve la garantía institucional — la garantía compite siempre con el principio de deferencia al legislador y con el de separación de poderes. $\mathrm{He}$ sostenido que la garantía institucional opera claramente en casos de disfuncionalidad institucional; esto es, tanto cuando existe peligro de que la institución se colapse, como cuando se frustran fines importantes de la institución. Pero conforme nos vamos alejando del riesgo de la disfuncionalidad institucional la garantía institucional va cediendo su espacio al principio de deferencia al legislador. 